\title{
Ultrasonography and Magnetic Resonance Cholangiopancreatography in Patients with Obstructive Jaundice
}

\author{
Pramod Chhetri, ${ }^{1}$ Hari Rana ${ }^{1}$
}

${ }^{1}$ Department of Radiodiagnosis, College of Medical Sciences-Teaching Hospital, Bharatpur, Chitwan, Nepal.

\begin{abstract}
Background: Jaundice is a common presenting symptom in patients with hepatobiliary disease. It can be categorized into medical and surgical jaundice and it is important to differentiate due to the different treatment options.

Methods: In this cross sectional study from Jan 2017 to June 2018, 84 consecutive patients with obstructive jaundice who underwent initial USG and then MRCP were included and their respective diagnosis compared keeping surgery and/or histopathology as the gold standard for final diagnosis.

Results: Out of 84 patients, $67.9 \%$ were females and $32.1 \%$ were males. The most common cause for obstructive jaundice was benign in $72.6 \%$ and malignancy in $27.4 \%$. Among the benign lesions choledocholithiasis was the most common $(57.4 \%)$ followed by pancreatitis $(26.2 \%)$. Cholangiocarcinoma was the most common malignant cause $(47.8 \%)$ followed by periampullary carcinoma $(26.2 \%)$. The sensitivity and specificity of USG in benign lesions was $67.2 \%$ and $87 \%$ respectively, and in malignancy $56 \%$ and $95 \%$ respectively. Similarly sensitivity and specificity of MRCP for benign lesions was $95.2 \%$ and $90.9 \%$ respectively, and for malignancy $95.75 \%$ and $98.45 \%$ respectively. Overall diagnostic accuracy of USG in benign and malignant causes was $76.62 \%$ and $84.52 \%$ respectively. Similarly overall diagnostic accuracy of MRCP for benign and malignant causes was $93.98 \%$ and $97.6 \%$ respectively.
\end{abstract}

Conclusions: USG is a good modality for Initial screening and for differentiating medical and surgical cause of jaundice. MRCP is a better modality with higher sensitivity, specificity and diagnostic accuracy for detecting pathology as compared to USG.

Keywords: MRCP; obstructive jaundice; USG.

\section{INTRODUCTION}

Jaundice is the most common presenting symptom in patients with hepatobiliary disease. 1 It can be categorized into medical and surgical jaundice and it is important to differentiate due to the different treatment options. ${ }^{2}$ The main cause of surgical jaundice is obstruction of the hepatobiliary tree, which can be intrahepatic or extrahepatic. Extra-hepatic is further subdivided into intraductal and extraductal. Intraductal obstruction can be due to many causes like blockage of biliary duct by calculi, stricture, neoplasm, parasites and primary sclerosing cholangitis. Extraductal obstruction can be due to compression of the biliary ducts by tumor, pancreatitis, cystic duct stones etc. ${ }^{3}$ In any patient showing clinical and biochemical features of obstructive jaundice, the main aim of radiologist is to confirm obstruction, its site, extent and location. ${ }^{4}$

Ultrasonography (USG) is the imaging modality of first choice for evaluating obstructive jaundice, and its ability to differentiate obstructive jaundice from non-obstructive jaundice is estimated to be about
90\%. ${ }^{1}$ Besides it is easily available, inexpensive, free from radiation and reproducible. The main disadvantages of USG is that the procedure is highly operator dependent, overlying bowel gas and patient body habitus which limits the examination of the distal common bile duct and the pancreas. ${ }^{5}$

Since its introduction by Wallner et al, ${ }^{6}$ Magnetic Resonance Cholangiopancreatography (MRCP) has undergone tremendous technical changes. In 1991,Wallner et al. introduced MRCP which used a breath hold 2D T-2 gradient echo sequence using Steady State Free Precession (SSFP). ${ }^{6}$ Marimoto improved image quality by introducing 3D SSFP sequences. $^{7}$ Modified Fast Spin Echo (FSE) sequences were introduced recently. These are the Rapid Acquisition with Rapid Enhancement sequence (RARE) and Half Fourier Acquisition Single Shot Turbo Spin Echo Sequences (HASTE). So, now HASTE \& RARE sequence are used.

Correspondence: Dr. Pramod Chhetri, Department of Radiodiagnosis, of Medical Sciences-Teaching Hospital, Bharatpur, Chitwan, Nepal. Email: dr.chhetripramod@gmail.com. Phone: +977-9845046687. Article received: 2019-10-12. Article accepted: 2020-02-12. 
MRCP visualize fluid in the biliary and pancreatic ducts as high signal intensity on heavily $\mathrm{T} 2$ weighted ( $\mathrm{T} 2 \mathrm{~W})$ sequences, thus exploiting the inherent differences in the $\mathrm{T} 2$-weighted contrast between stationary fluid-filled structures in the abdomen (which have a long $\mathrm{T} 2$ relaxation time) and adjacent soft tissue (which has a much shorter $\mathrm{T}$ 2 relaxation time). Fluids within the biliary tree and pancreatic duct appear high signal intensity on MRCP, while surrounding tissue is of reduced signal intensity. ${ }^{6,7}$ Since MRI was recently installed in the department, this study was thus undertaken to compare the role of MRCP in surgical jaundice after traditionally undergoing initial USG.

\section{METHODS}

This was a hospital based cross-sectional study from January 2017 to June 2018 on 84 consecutive patients with obstructive jaundice who were referred for USG and then MRCP in the Department of Radiology. Patients were preferably advised NPO for 4-6 hours prior to USG examination (Toshiba Applio 500). The examination included scanning of the liver, gallbladder, intrahepatic ducts, CBD, pancreas and the periampullary region. Patient with medical cause for their jaundice were excluded. USG findings and diagnosis was made for each of the patients with obstructive jaundice.

These patients were subsequently advised for MRCP by the surgeons (Siemens 3 Tesla Magnetom Spectra) either the same or next day. The usual contraindications for MRI were noted before MRCP. All patients were advised overnight fasting to avoid fluid collection in the stomach and duodenum and to distend the gallbladder. Patients were examined in following sequences. All these sequences are taken with respiratory triggering software.

In axial sequence:

- T2 HASTE (TR: $2000 \mathrm{~ms}$, TE: $149 \mathrm{~ms}$ )

- T2 HASTE FAT SAT (TR: 2000ms, TE: $105 \mathrm{~ms}$ )

- T2 FAT SAT TSE- propeller sampling (TR: $1600 \mathrm{~ms}$, TE: $90 \mathrm{~ms})$

- T1 gradient in-phase (TR: $1800 \mathrm{~ms}, \mathrm{TE}: 2.8 \mathrm{~ms}, \mathrm{IR}$ : sequence T1: 1190ms)

In coronal sequence:

- T2 HASTE (TR: 2000ms, TE: 113ms)

- T2 SPACE 3D

In coronal thick slab:

- T2 HASTE FAT SAT

After USG and MRCP, their respective diagnosis was compared keeping surgery and/or histopathology as the gold standard for final diagnosis. After completion, data collected were compiled and analyzed by SPSS (version 20.0). Appropriate statistical tools were used to find out the significance of the variables.

\section{RESULTS}

Eighty four patients with surgical jaundice underwent both USG and MRCP examination. The final diagnosis was made on surgery and/or after histopathology. Patients who did not undergo surgery were followed up and diagnosis made clinically with laboratory correlation. Among 84 patients, $67.9 \%(\mathrm{n}=57)$ were female and $32.1 \%$ $(n=27)$ were male. The age ranged from 10 to 89 years, with a mean age of $53 \pm 19$ years SD. Out of 84 patients, $72.6 \%(\mathrm{n}=61)$ had benign disease and $27.4 \% \quad(n=23)$ had malignant disease. As shown in Table 1, choledocholithiasis was the most common benign cause accounting for $57.4 \%$ $(\mathrm{n}=35)$ followed by pancreatitis in $27.8 \%(\mathrm{n}=17)$, choledochal cyst in $8.2 \%(\mathrm{n}=5)$ and cholangitis in $3.3 \%(\mathrm{n}=2)$, Mirizzi syndrome and post operative stricture $(\mathrm{n}=1)$.

\begin{tabular}{|c|c|c|}
\hline Benign cause & Frequency & Percent (\%) \\
\hline Choledocholithiasis & 35 & 57.4 \\
\hline Pancreatitis & 17 & 27.8 \\
\hline Choledochal cyst & 5 & 8.2 \\
\hline $\begin{array}{l}\text { Primary Sclerosing Chol- } \\
\text { angitis }\end{array}$ & 2 & 3.3 \\
\hline Mirizzi syndrome & 1 & 1.6 \\
\hline Post operative strictures & 1 & 1.6 \\
\hline
\end{tabular}

As shown in Table 2, cholangiocarcinoma was the most common malignant cause $(47.8 \%)$, followed by periampullary carcinoma $(21.7 \%)$, pancreatic head tumor $(17.4 \%)$ and infiltrating gallbladder carcinoma (13\%).

\begin{tabular}{|lcc|}
\hline \multicolumn{3}{|c|}{ Table 2. Malignant causes of jaundice. $(\mathbf{n}=\mathbf{2 3})$} \\
\hline Malignant cause & Frequency & Percent (\%) \\
Cholangiocarcinoma & 11 & 47.82 \\
Periampullary carcinoma & 5 & 21.7 \\
$\begin{array}{llc}\text { Pancreatic head tumor } \\
\text { Infiltrating gallbladder }\end{array}$ & 4 & 17.4 \\
carcinoma & 3 & 13 \\
\hline
\end{tabular}

All 35 patients with diagnosis of choledocholithiasis underwent surgery and were thus confirmed. Of these 35 cases, USG detected 25 and all were in the proximal and mid CBD. In the remaining 10 cases, USG could not visualize the distal CBD calculi due to overlying bowel gas. USG thus had a sensitivity and specificity of 77.78 $\%$ and $93.88 \%$. MRCP, on the other hand, diagnosed 34 of the 35 cases with choledocholithiasis. One case was misdiagnosed as pneumobilia, which was later found to be a calculus on surgery. The sensitivity and specificity of MRCP was thus $97.22 \%$ and $97.92 \%$ respectively.

There were 17 patients with clinically confirmed acute pancreatitis based on increased serum lipase and amylase level. USG showed enlarged pancreas with peri-pancreatic fluid collection in 11 cases 
compressing the distal CBD. In the remaining 6 cases, USG could not visualize the pancreas adequately ( 2 were obese patient and 4 had excessive overlying bowel gas). Nevertheless, mildly dilated proximal CBD was noted. Thus, USG had a sensitivity and specificity of $73.91 \%$ and $98.36 \%$ respectively. MRCP, on the other hand, detected the enlarged edematous pancreas causing distal CBD compression in 16 cases. In the remaining one case, visualization of the pancreas was obscured by artifact caused by surrounding ascitic fluid. The sensitivity and specificity of MRCP was $94.44 \%$ and $98.48 \%$ respectively.

There were five patients with choledochal cysts confirmed on surgery. Diagnosis on USG was made in 3 of these cases. All were Todani's type I choledochal cyst. In the remaining 2 cases, preoperative USG diagnosis was not made. USG thus had a sensitivity and specificity of $71.43 \%$ and $98.70 \%$. MRCP however diagnosed all the 5 cases of choledochal cysts. Four of these patients had type I choledochal cysts. The remaining one case which was diagnosed as type I on USG, MRCP further demonstrated small intrahepatic biliary duct cysts which were missed on USG due to the small size. Thus the diagnosis was upgraded to Todani's type IVa after MRCP.

There were 2 patients with known primary sclerosing cholangitis (with positive serum markers) who were referred for exacerbation of their jaundice and elevation of serum alkaline phosphatase. USG showed heterogeneous liver parenchyma with increased echotexture and mildly dilated intrahepatic ducts. On the other hand, MRCP clearly demonstrated mild thickening of the CBD and irregular intrahepatic ducts with focal narrowing \& dilatations. There was one patient with prior history of cholecystectomy with choledocholithotomy who presented with recent onset jaundice. USG showed dilated proximal CBD with abrupt distal narrowing. The cause could not be ascertained on USG. MRCP however demonstrated the abrupt smooth CBD narrowing. The diagnosis of post operative stricture was confirmed after surgery.

There was one patient with Mirizzi syndrome confirmed on surgery. There was gross GB distension with multiple intraluminal calculi. USG could not visualize the cystic duct stone. MRCP however demonstrated the calculus in the cystic duct compressing the CBD causing proximal dilatation. Eleven patients with cholangiocarcinoma underwent surgery with histopathology confirmation. USG detected only 5 cases of the 11 cases, with 2 cases of Klatskin's tumor and 3 with mid -distal CBD thickening. In the remaining 6 cases, USG missed the distal CBD mass. Sensitivity and specificity of USG was thus $64.71 \%$ and 98.51 $\%$. MRCP, on the other hand, diagnosed 10 of these 11 cases. One case was misdiagnosed as benign stricture on MRCP. The sensitivity and specificity of MRCP was $91.67 \%$ and $98.7 \%$ respectively.

Four patients with pancreatic head tumor underwent surgery. Of these 4 cases, USG detected the pancreatic mass in 2 cases and in the remaining USG could not visualize the pancreatic mass confidently. Thus sensitivity and specificity of USG was $50 \%$ and $98.8 \%$. On MRCP preoperative diagnosis was made in all 4 cases of pancreatic head tumor. MRCP showed mass in the head of pancreas causing the double duct sign. Five patients with periampullary carcinoma were diagnosed after endoscopic biopsy. Out of these 5 cases, USG detected 4 cases with a sensitivity and specificity of $80 \%$ and $98.75 \%$ respectively. MRCP however diagnosed all 5 cases of periampullary carcinoma. Two patients with USG diagnosis of infiltrating gallbladder carcinoma underwent USG guided biopsy and were confirmed on histopathology. In another patient with USG diagnosis of hilar cholangiocarcinoma turned out to be gall bladder neck mass with CBD infiltration on surgery. Thus sensitivity and specificity of USG was $67.7 \%$ and $98.8 \%$ respectively. MRCP however diagnosed all 3 cases of infiltrating gallbladder carcinoma.

Table 3 summarizes the sensitivity and specificity of USG and MRCP in obstructive jaundice.

\begin{tabular}{|c|c|c|c|c|c|c|}
\hline \multicolumn{7}{|c|}{$\begin{array}{l}\text { Table 3. Sensitivity and specificity of USG and MRCP for } \\
\text { obstructive jaundice. }\end{array}$} \\
\hline $\begin{array}{l}\text { Final Diagno- } \\
\text { sis }\end{array}$ & $\begin{array}{l}\text { Diag- } \\
\text { nosis } \\
\text { by } \\
\text { USG }\end{array}$ & $\begin{array}{l}\text { Sensi- } \\
\text { tivity } \\
\text { of } \\
\text { USG }\end{array}$ & $\begin{array}{l}\text { Speci- } \\
\text { ficity } \\
\text { of } \\
\text { USG }\end{array}$ & $\begin{array}{l}\text { Diag- } \\
\text { nosis } \\
\text { by } \\
\text { MRCP }\end{array}$ & $\begin{array}{l}\text { Sensi- } \\
\text { tivity } \\
\text { of } \\
\text { MRCP }\end{array}$ & $\begin{array}{l}\text { Speci- } \\
\text { ficity } \\
\text { of } \\
\text { MRCP }\end{array}$ \\
\hline $\begin{array}{l}\text { Choledocho- } \\
\text { lithiasis } \\
(\mathrm{n}=35)\end{array}$ & 25 & $77.8 \%$ & $93.8 \%$ & 34 & $97.2 \%$ & $97.9 \%$ \\
\hline $\begin{array}{l}\text { Pancreatitis } \\
(\mathrm{n}=17)\end{array}$ & 11 & $73.9 \%$ & $98.3 \%$ & 16 & $94.4 \%$ & $98.8 \%$ \\
\hline $\begin{array}{l}\text { Post-operative } \\
\text { strictures } \\
(\mathrm{n}=1)\end{array}$ & 1 & $100 \%$ & $100 \%$ & 1 & - & - \\
\hline $\begin{array}{l}\text { Choledochal } \\
\text { cyst } \\
n=5\end{array}$ & 3 & $71.4 \%$ & $98.7 \%$ & 5 & $100 \%$ & $100 \%$ \\
\hline $\begin{array}{l}\text { Sclerosing } \\
\text { cholangitis } \\
(\mathrm{n}=2)\end{array}$ & 0 & - & - & 2 & $100 \%$ & $100 \%$ \\
\hline $\begin{array}{l}\text { Mirizzi syn- } \\
\text { drome }(\mathrm{n}=1)\end{array}$ & 0 & - & - & 1 & - & - \\
\hline $\begin{array}{l}\text { Cholangiocar- } \\
\text { cinoma }(\mathrm{n}=11)\end{array}$ & 5 & $64.7 \%$ & $98.5 \%$ & 10 & $91.7 \%$ & $98.7 \%$ \\
\hline $\begin{array}{l}\text { Pancreatic } \\
\text { head tumor } \\
(\mathrm{n}=4)\end{array}$ & 2 & $50 \%$ & $98.8 \%$ & 4 & $100 \%$ & $100 \%$ \\
\hline $\begin{array}{l}\text { Periampullary } \\
\text { carcinoma } \\
(\mathrm{n}=5)\end{array}$ & 4 & $80 \%$ & 98.75 & 5 & $100 \%$ & $100 \%$ \\
\hline $\begin{array}{l}\text { Infiltrating GB } \\
\text { carcinoma } \\
(\mathrm{n}=3)\end{array}$ & 2 & $66.7 \%$ & $98.8 \%$ & 3 & $100 \%$ & $100 \%$ \\
\hline
\end{tabular}


Table 4 summarizes the sensitivity, specificity and diagnostic accuracy of USG for benign and malignant disease causing obstructive jaundice.

\begin{tabular}{|llllll|}
\hline Table & 4. & Sensitivity, specificity & and & diagnostic \\
accuracy of & USG for obstructive jaundice. & \\
\hline USG & Sensitivity & Specificity & Accuracy & $\chi^{2}$-value p-value \\
Benign & $65.57 \%$ & $86.96 \%$ & $71.4 \%$ & 18.44 & $<0.001^{*}$ \\
Malignant & $56 \%$ & $95 \%$ & $84.5 \%$ & 28.84 & $<0.001 *$ \\
\hline * Statistically significant at $5 \%$ level of significance & \\
\hline
\end{tabular}

Table 5 summarizes the sensitivity, specificity and diagnostic accuracy of MRCP for benign and malignant disease causing obstructive jaundice

\begin{tabular}{|lccccc|}
\hline Table 5. Sensitivity, specificity and diagnostic \\
accuracy of MRCP for obstructive jaundice. \\
\hline USG & Sensitivity & Specificity & Accuracy $\chi^{2}$-value p-value \\
Benign & $95.20 \%$ & $90.90 \%$ & $93.9 \%$ & 60.4 & $<0.001^{*}$ \\
Malignant & $95.75 \%$ & $98.45 \%$ & $97.6 \%$ & 74.24 & $<0.001 *$ \\
\hline * Statistically significant at $5 \%$ level of significance \\
\hline
\end{tabular}

\section{DISCUSSION}

Radiologists play a pivotal role in diagnosing obstructive jaundice helping surgeons decide the appropriate line of management. This study aims to establish and compare the role of USG and MRCP in obstructive jaundice keeping histopathological / postsurgical findings as the gold standard for final diagnosis.

In this study, there were $67.9 \%$ females and $32.2 \%$ males, showing female preponderance. Similarly Gameraddin et al. ${ }^{8}$ also found females to be more frequently affected by obstructive jaundice than males. In their study of 150 patients, there were $65.3 \%$ females and $34.6 \%$ males. In this study, $72.6 \%$ had a benign cause for their jaundice and malignancy in $27.4 \%$. Thus a benign lesion was more common. Sharma et al. ${ }^{9}$ noted $53 \%$ of their patients had benign cause for obstructive jaundice and malignancy in $47 \%$. Also Ranjan et al. ${ }^{10}$ found benign lesions in $90 \%$ and malignancy in $10 \%$ in 40 patients.

Choledocholithiasis was the most common cause for obstructive jaundice. USG detected 25 of the 35 cases and in the remaining USG could not visualize the distal CBD calculi. Thus, the sensitivity and specificity of USG was $71.43 \%$ and $93.88 \%$ respectively. MRCP diagnosed 34 cases while one was misdiagnosed as pneumobilia. Its sensitivity and specificity was $97.22 \%$ and $97.9 \%$ respectively. In a similarly study by Mohammadali et al. ${ }^{11}$ USG had a sensitivity and specificity of $84 \%$ and $86 \%$ and MRCP of $95.24 \%$ and $95.65 \%$ respectively. Similar results were also reported by Safa et al. ${ }^{12}$ In their study of 80 patients with obstructive jaundice, 29 patients had choledocholithiasis. USG detected 11 cases with a sensitivity and specificity of $37.9 \%$ and $96.2 \%$ respectively while MRCP detected all cases. In 17 patients with acute pancreatitis in this study, the sensitivity and specificity of USG and MRCP was $73.91 \%$ and $98.36 \%$ and $94.44 \%$ and $98.48 \%$ respectively. In a similar study by Jiwani et al. ${ }^{13}$ in 8 patients with pancreatitis, USG detected 5 and MRCP detected 7 cases with sensitivity and specificity of USG $83.3 \%$ and $94.7 \%$ and that of MRCP $87.5 \%$ and $97.3 \%$ respectively. MRCP missed one case of pancreatitis which was associated with ascitis. Similarly in our study, the one case missed on MRCP, visualization of the pancreas was obscured by artifact caused by surrounding ascitic fluid.

In the 2 patents with known primary sclerosing cholangitis, MRCP better depicted the ductal thickening and dilatation than USG. In a study on 185 patients, Dave et al. ${ }^{14}$ similarly concluded that MRCP has high sensitivity and specificity for the diagnosis of primary sclerosing cholangitis. There was one patient with postoperative stricture with jaundice, having prior history of cholecystectomy with choledocholithotomy. USG showed dilated CBD with abrupt distal narrowing. MRCP however demonstrated the smooth abrupt narrowing with no wall or luminal abnormality. Similarly Safa et al ${ }^{12}$ in 6 cases of post operative strictures, MRCP detected all cases correctly while USG could not make the preoperative diagnosis. Thus, MRCP was a better imaging modality.

In this study the sensitivity and specificity of USG in the diagnosis of cholangiocarcinoma was $64.71 \%$ and $98.51 \%$ respectively. In 6 cases of the 11 cases, USG could not detect the mass due to their distal location in the terminal CBD. MRCP had a sensitivity and specificity of $91.67 \%$ and $98.7 \%$ respectively. One case misdiagnosed as benign stricture on MRCP had cholangiocarcinoma of the distal CBD. In a similar study by Singh et al. ${ }^{15}$ USG detected 4 of the 6 cases of cholangiocarcinoma, with sensitivity and specificity of $66.67 \%$ and $100 \%$ respectively. On MRCP they diagnosed all 6 cases. Pavone et $\mathrm{al}^{16}$ found sensitivity and specificity of MRCP in diagnosis of cholangiocarcinoma to be $80 \%$ and $98 \%$ respectively.

In periampullary carcinoma, the sensitivity and specificity of USG was $88 \%$ and $98.7 \%$ while MRCP detected all the 5 cases correctly. In a similar study by Mohhamadali et al. ${ }^{11}$ in 100 patients, USG had a sensitivity and specificity of 91.67\% and $97.73 \%$ while MRCP had sensitivity and specificity of $90.9 \%$ and $98.56 \%$ respectively. There were 4 cases of pancreatic head carcinoma causing CBD obstruction confirmed on surgery. USG could detect only 2 while MRCP preoperatively diagnosed all 4 cases. The sensitivity and specificity of USG was thus $50 \%$ 
and $98.8 \%$. In a study by Al-Obaidi et al. ${ }^{17}$, USG detected 12 of the 33 cases of pancreatic head tumor with sensitivity and specificity of $66.3 \%$ and $80.7 \%$ respectively, while MRCP detected 30 of the 33 cases with sensitivity and specificity of $90 \%$ and $97.8 \%$ respectively. Similarly Haminem et al. ${ }^{18}$ in a study of 66 patients with pancreatic head tumor found sensitivity and specificity of MRCP of $91 \%$ and $95 \%$ respectively.

In 3 patients with gallbladder carcinoma with CBD infiltration, USG correctly diagnosed 2 cases wile MRCP diagnosed all the three cases preoperatively. Thus sensitivity and specificity of USG was $67.7 \%$ and $98.8 \%$ respectively. Similarly, in 7 cases of gallbladder carcinoma with CBD infiltration Jiwani et $\mathrm{al}^{13}$ diagnosed 6 of these cases on USG with a sensitivity of $75 \%$ and specificity of $97.92 \%$. MRCP detected all the 7 cases.

In this study, USG diagnosed 40 of the 61 benign lesions causing jaundice. Thus USG had a sensitivity, specificity and accuracy of $65.57 \%$, $86.96 \%$ and $71.43 \%$ respectively. However, USG could diagnose only 13 of the 23 cases with malignant jaundice thus having sensitivity, specificity and accuracy of $56 \%, 95 \%$ and $84 \%$ respectively. Likewise MRCP had a sensitivity, specificity and accuracy of $95.2 \%, 90.9 \%$ and $97.62 \%$ respectively for benign cause of jaundice and a sensitivity, specificity and accuracy of $95.75 \%, 98.45 \%$ and $97.62 \%$ respectively for malignant jaundice. In a similar study by Amandeep et al. ${ }^{19}$ USG had sensitivity, specificity and accuracy of $80 \%, 77 \%, 95.83 \%$ respectively for benign lesions and $79.17 \%, 96.15 \%$ and $88 \%$ respectively for malignant jaundice. MRCP, on the other hand, had sensitivity, specificity and accuracy of $100 \%, 95.83 \%$ and $98 \%$ respectively for benign causes and $95.83 \%, 100 \%$, and $98 \%$ respectively for malignant causes. Similarly Verma et $\mathrm{al}^{20}$ on USG found sensitivity and specificity of $85.3 \%$ and $88.4 \%$ respectively for benign causes and $92.3 \%$ and $86 \%$ respectively on MRCP, while the sensitivity and specificity for malignant causes were $88.4 \%$ and $85.3 \%$ on USG and $94.2 \%$ and $95 \%$ on MRCP respectively.

\section{CONCLUSIONS}

In conclusion, USG is a good modality for initial screening and for differentiating medical and surgical cause of jaundice. MRCP is a better modality with higher sensitivity, specificity and diagnostic accuracy for detecting pathology as compared to USG.

\section{REFERENCES}

1. Seltzer SE, Jones B. Imaging the hepatobiliary system in acute disease. Am J Roentgenol. 1980;135(2):407-16

2. Ferrari FS, Fantozzi F, Tasciotti L, Vigni F, Scotto F, Frasci P. US, MRCP, CCT and ERCP: a comparative study in 131 patients with suspected biliary obstruction. Med Sci Monit. 2005;11(3):8-18

3. Khurram M, Durrani A, Hassan A, Ashfaq S. Endoscopic Retrograde Cholangiopancreaticographic Evaluation of patient with obstructive jaundice. J Coll Physicians Surg. 2003;13:325-8

4. Pearls JE. Advanced MRI -From Head to Toe 2002. Page 211-46.

5. Lerttumnongtum $P$, Muttarak $M$, Wasanavijit $\mathrm{K}$. Clinics in diagnostic imaging (79). Ampulla of Vater carcinoma. Singapore Med J. 2002;43:591-6.

6. Wallner BK, Schumacher KA, Weidenmaier W, Friedrich JM. Dilated biliary tract: evaluation with MR cholangiography with a T2-weighted contrast-enhanced fast sequence. Radiology. 1991;181(3):805-8.

7. Morimoto K, Shimoi M, Shirakawa T, Aoki Y, Choi S, Miyata Y, et al. Biliary obstruction: evaluation with three-dimensional MR cholangiography. Radiology. 1992; 183(2):57880

8. Gameraddin M, Omer S, Salih S, Elsayed SA,

Alshaikh A. Sonographic Evaluation of Obstructive Jaundice. Open Journal of Medical Imaging. 2015;Vol.5, No.1:6.

9. Sharma P, Lalchan S, Tiwari PK. Journal of Chitwan Medical College 2017; 7 (20): 15-18. Journal of Chitwan Medical College. 2017;7 (20):15-8.

10. Ranjan A KA, Jha N K, Jain V K. An observation on clinical presentation and management of obstructive jaundice. Int J Sci Res. 2017;6(8).

11. S Jiwani M, J Banode P, D Kharche A, A Jiwani A, Vaidhya SV. Role of Magnetic Resonance Cholangiopancreatography in Cases of Obstructive Jaundice in Correlation with Ultrasonography. IJRSMS. 2016;2:70-84.

12. Safa A-O, Mohammed R, Atheer A. The role of ultrasound and magnetic resonance imaging in the diagnosis of obstructive jaundice. The Iraqi Postgraduate Medical Journal. 2007;6.

13. S Jiwani M, J Banode P, D Kharche A, A Jiwani A, Vaidhya SV. Role of Magnetic Resonance Cholangiopancreatography in Cases of Obstructive Jaundice in Correlation with Ultrasonography. IJRSMS. 2016;2:70-84.

14. Dave M, Elmunzer BJ, Dwamena BA, Higgins PD. Primary sclerosing cholangitis: metaanalysis of diagnostic performance of MR cholangiopancreatography. 2010;256(2):387-96

15. Singh A, Mann HS, Thukral CL, Singh NR. 
Diagnostic accuracy of MRCP as compared to ultrasound/CT in patients with obstructive jaundice. J Clin Diagn Res. 2014;8(3):103.

16. Pavone P, Laghi A, Catalano C, Panebianco V, Fabiano S, Passariello R. MRI of the biliary and pancreatic ducts. Eur Radiol. 1999;9(8):151322.

17. Al-Obaidi S. The role of ultrasound and magnetic resonance imaging in the diagnosis of obstructive jaundice. Iraqi Academic Scientific Journal. 2007;6(1):7-17.

18. Tamm EP, Silverman PM, Charnsangavej C,
Evans DB. Diagnosis, staging, and surveillance of pancreatic cancer. Am J Roentgenol. 2003;180(5):1311-23.

19. Singh A, Mann HS, Thukral CL, Singh NR. Diagnostic accuracy of MRCP as compared to ultrasound/CT in patients with obstructive jaundice. J Clin Diagn Res. 2014;8(3):103.

20. Verma S SS, Gupta P, Munsh A,. Obstructive Jaundice- Aetiological Spectrum, Clinical, Biochemical And Radiological Evaluation At A Tertiary Care Teaching Hospital. J Trop Med. 2010;7:8.

Citation: Chhetri P, Rana H. Ultrasonography and Magnetic Resonance Cholangiopancreatography in Patients with Obstructive Jaundice. JCMS Nepal. 2020; 16(1):6-11 